\title{
Sentinel surveillance of child maltreatment cases presenting to Canadian emergency departments
}

\author{
Aimée Campeau ${ }^{1}$, Lil Tonmyr $^{1 *}$ (D), Erik Gulbransen²${ }^{2}$ Martine Hébert $^{3}$, Steven McFaull ${ }^{1}$ and Robin Skinner ${ }^{1}$
}

\begin{abstract}
Background: The Canadian Hospitals Injury Reporting Prevention Program (CHIRPP) is a sentinel surveillance program that collects and analyzes data on injuries and poisonings of people presenting to emergency departments (EDs) at 11 pediatric and eight general hospitals (currently) across Canada. To date, CHIRPP is an understudied source of child maltreatment (CM) surveillance data. This study: (1) describes CM cases identified in the CHIRPP database between1997/98 to 2010/11; (2) assesses the level of CM case capture over the 14-year period and; (3) uses content analysis to identify additional information captured in text fields.

Methods: We reviewed cases of children under 16 whose injuries were reported as resulting from CM from 1997/ 98 to 2010/11. A time trend analysis of cases to assess capture was conducted and content analysis was applied to develop a codebook to assess information from text fields in CHIRPP. The frequency of types of CM and other variables identified from text fields were calculated. Finally, the frequency of types of CM were presented by age and gender.
\end{abstract}

Results: A total of 2200 CM cases were identified. There was a significant decrease in the capture of CM cases between 1999 and 2005. Physical abuse was the most prevalent type (57\%), followed by sexual assault (31\%), unspecified maltreatment (7\%), injury as the result of exposure to family violence (3\%) and neglect (2\%). Text fields provided additional information including perpetrator characteristics, the use of drugs and/or alcohol during the injury event, information regarding the involvement of non-health care professionals, whether maltreatment occurred during a visitation period with a parent and, whether the child was removed from their home.

Conclusions: The findings from this initial study indicate that CHIRPP could be a complimentary source of CM data. As an injury surveillance system, physical abuse and sexual assault were better captured than other types of CM. Text field data provided unique information on a number of additional details surrounding the injury event, including risk factors.

Keywords: Child maltreatment, Physical abuse, Sexual abuse, Neglect, Exposure to family violence, Emergency department data, Public health surveillance

\footnotetext{
* Correspondence: lil.tonmyr@canada.ca

${ }^{1}$ Public Health Agency of Canada, Ottawa, ON, Canada

Full list of author information is available at the end of the article
}

(c) The Author(s). 2019 Open Access This article is distributed under the terms of the Creative Commons Attribution 4.0 International License (http://creativecommons.org/licenses/by/4.0/), which permits unrestricted use, distribution, and reproduction in any medium, provided you give appropriate credit to the original author(s) and the source, provide a link to the Creative Commons license, and indicate if changes were made. The Creative Commons Public Domain Dedication waiver (http://creativecommons.org/publicdomain/zero/1.0/) applies to the data made available in this article, unless otherwise stated. 


\section{Background}

Child maltreatment (CM) includes physical and sexual abuse, neglect, emotional maltreatment, and exposure to intimate partner violence (IPV) [1]. It has been well established that $\mathrm{CM}$ adversely impacts the development and well-being of children throughout their lives [2]. To understand the scope of this problem, evidence is collected from multiple sources such as child welfare data, police data, mortality and morbidity data, and population health and social surveys [3]. Examining information from diverse data sources can help to provide a more nuanced picture of $\mathrm{CM}$ than can be gained from any one source [4-6]. For instance, the Canadian Incidence Study of Reported Child Abuse and Neglect (CIS) provides information regarding reported CM investigations by child welfare [7]. However, official substantiated cases of CM only represent the "tip of the iceberg" as they do not include information about unreported CM or cases investigated by the police [7]. Selfreported population health data provides the most accurate national estimates of $\mathrm{CM}$, although concerns have been raised regarding the willingness of respondents to disclose childhood abuse and neglect $[4,8]$.

In Canada, healthcare professionals are mandated to report suspected $\mathrm{CM}$ to child welfare [9]. Healthcare providers are on the frontlines to detect $\mathrm{CM}$ and EDs are critical entry points for children who present with injuries due to more severe cases of abuse or neglect $[10,11]$. However, the number of child abuse reports from EDs tends to be low $[9,12,13]$ and problems with identification methods have been noted [14, 15]. The rates of child abuse and neglect in children presenting to ED have been reported from $0.1-2 \%$, although older studies have reported rates as high as 10\% [16]. Further, evidence suggests that 20 to $30 \%$ of children who died from $\mathrm{CM}$ had previous documented health care visits [17]. In Canada, a limited number of studies have examined children presenting to EDs and these have focused on brain or head injuries related to CM [18-20].

An understudied source of CM surveillance data is the Canadian Hospitals Injury Reporting Prevention Program (CHIRPP). CHIRPP is a sentinel surveillance program that collects and analyzes information on injuries and poisonings of patients who present to the EDs of participating hospitals (currently 19) across Canada. Historically, CHIRPP has not been used as a source of CM surveillance, however, recent efforts have been made to explore intentional injury reports in CHIRPP [21]. Due to its focus on pediatric hospitals, CHIRPP potentially provides a valuable source of $\mathrm{CM}$ data. To our knowledge, there are no studies that have exclusively examined child maltreatment using the CHIRPP database. This study: (1) describes CM cases identified in the CHIRPP database between1997/98 to 2010/11; (2) assesses the level of CM case capture over the 14-year period and; (3) uses content analysis to identify additional information captured in text fields.

\section{Methods \\ Sample}

The CHIRPP is a sentinel surveillance program (injuries and poisonings) operating in the EDs of 11 pediatric and eight general hospitals participating in CHIRPP across Canada. When an injured person presents to a participating emergency room, they (or the accompanying caregiver) are asked to complete a one-page questionnaire including their accounts of the circumstances surrounding the injury ("what went wrong") [22, 23]. The attending physician or hospital staff add clinical details such as the injured body part, the nature of the injury (e.g. fracture, concussion, poisoning), whether the injury was intentional (i.e. sexual assault, maltreatment), unintentional (i.e. accidental), or undetermined/unknown, the location where the injury occurred, and any treatment received. These details along with extracts from patients' accounts are entered into the CHIRPP database by data coders [23]. Patients' accounts of the injury event are condensed into text fields (maximum 120 characters for the time period of this study).

\section{Eligibility criteria}

In CHRIPP data there are two codes that identify violence against children. Cases associated with $\mathrm{CM}$ were selected if: (1) the intent was coded as 'sexual assault by bodily force' (CHIRPP intent code 12) or 'maltreatment by a parent or caregiver' (CHIRPP intent code 13) or; (2) the text field contained various keywords (e.g. "abuse", "rape", "assault") identifying any cases which may have been misclassified; (3) the patient was under 16 years (191 months) and; (4) the injury occurred between April 1, 1997 and March 31, 2011. This period was chosen for consistency of coding and data capture $[22,23]$. The CHIRPP database underwent an upgrade in 1996 and again in 2011 to eCHIRPP (an electronic version of the surveillance system).

\section{Time trend analysis}

To quantify CHIRPPs capture of CM cases over the study period, the data were normalized:

for each year the number of CM cases for children less than 16 years $(0-191$ months) was divided by the total number of CHIRPP cases for children less than 16 years of age, times 100,000.

Joinpoint regression [24] was used to assess the trend by locating inflection points (joinpoints) and calculating the Annual Percent Change (APC) of each identified segment according to the methods described by the National Cancer Institute [25]. Joinpoint regression software tests whether the APC of each segment is significantly different from zero at the alpha $=0.05$ level and produces a $95 \%$ confidence 
interval (CI). The weighted average (AAPC) was also calculated for the entire time span.

\section{Coding text fields \\ Codebook development}

Content analysis [26] was used to examine text fields to identify additional data from $\mathrm{CM}$ cases identified through the CHRIPP codes. A codebook was designed by four researchers (AC, EG, LT and MH) to establish consistent guidelines in order to abstract data from text fields. A 10\% random sample of text fields in English and French was removed from the overall sample and each coder independently identified key themes, patterns, and emerging trends in order to develop their own version of a codebook. All codebooks were shared among the coders for discussion and feedback. Once core variables were identified, definitions, guidelines and examples were developed. Decisions were then made regarding which codes to keep, expand, or exclude, resulting in a single version of the codebook for reference purposes. For example, the category first identified as "injury due to exposure to IPV" was expanded to "injury due to exposure to family violence" as some cases reported violence between family members other than intimate partners or between family members and other adults. In these cases, the child or adolescent was physically harmed as a result of the violence.

\section{Codebook testing}

In order to test consistency of code application, two teams of coding partners (AC, EG and LT, MH) independently coded the first 100 text fields and compared results. When it was established that coders were using the codebook consistently, coding of the text fields in the dataset began. Minor changes were made to coding guidelines at this stage as questions arose about specific coding decisions, and to be inclusive of emerging data patterns.

\section{Application of codebook}

Once testing of the codebook was completed, text fields were divided between two coding teams (1100 for each team) and recorded into separate Excel files. One group of coding partners coded English and French text fields, while the second coded English only. Coding partners compared their coding decisions for all variables and calculated agreement for type of maltreatment. Overall, inter-coder agreement was $85 \%$ for type of $\mathrm{CM}$. Although inter-coder agreement was not calculated for all variables, each was checked by coding partners to ensure consistency. When discrepancies occurred, coding partners discussed the issue and made a joint decision as to how to proceed. Any discrepancies or questions that could not be resolved between coding partners were brought to the other team members and discussed until consensus was reached.

Once both coding teams completed their checks, descriptions of coded variables were consolidated into one excel sheet along with existing CHIRPP variables (e.g. age, gender) and assigned numerical values. Written descriptions of certain variables (i.e., additional information) were kept in separate excel files with a corresponding ID number for reference purposes. Descriptive statistics were then conducted to assess the frequency of selected variables identified from text fields. Finally, the frequency of types of $\mathrm{CM}$ were presented by age and gender.

\section{Results \\ Eligible cases}

A total of $2112 \mathrm{CM}$ cases were identified using intent codes for children under 16 years over a 14-year period (1997/98 to 2010/11). In addition, 96 cases were identified through a keyword search. Six duplicates and two miscoded cases were excluded, resulting in a final sample of 2200 cases representing $11 \%$ of intentional injury cases for this period. The majority of the patients in the overall sample were female $(59 \%)$ and the median age was 7.8 years.

\section{Time trend analysis}

Figure 1 shows the results of the Joinpoint regression analysis. Two joinpoints were identified: 1999/00 and 2005/06. Between fiscal years 1997/98 and 1999/00 there was a nonsignificant increasing trend of $26.0 \%$ (CI: - 19.7,97.8). Between $1999 / 00$ and 2005/06 there was a decreasing trend of $12.6 \%$ (CI: $-21.3,-2.5$ ). From $2005 / 06$ to $2010 / 11$ there was a slight increase of $6.4 \%$ (CI: $-5.2,19.4)$, but this was not statistically significant. The overall average annual percent change (AAPC) was not considered to be an appropriate representation of the trend and is not reported.

\section{Text field themes}

Table 1 presents unique information obtained from text fields. Of the sample, $680(31 \%)$ cases were the result of 'sexual assault by bodily force' and 1520 (69\%) were the result of 'maltreatment by a parent or caregiver.' When categorized by CM type, injury due to physical abuse was the most prevalent form of maltreatment, followed by sexual assault, unspecified maltreatment, injury due to exposure to family violence and neglect. Emotional maltreatment was never recorded on its own but identified as the co-occurring form of abuse in less than $1 \%$ of cases (data not shown). Co-occurring abuse was identified in $5 \%$ of cases (data not shown).

The CHIRPP disposition code for fatalities, combined with data from text fields, revealed that eight children $(<$ $1 \%$ ) died from CM. These fatalities occurred mostly among male children ranging in ages from 0 to 3.5 years from head related injuries (data not shown). 


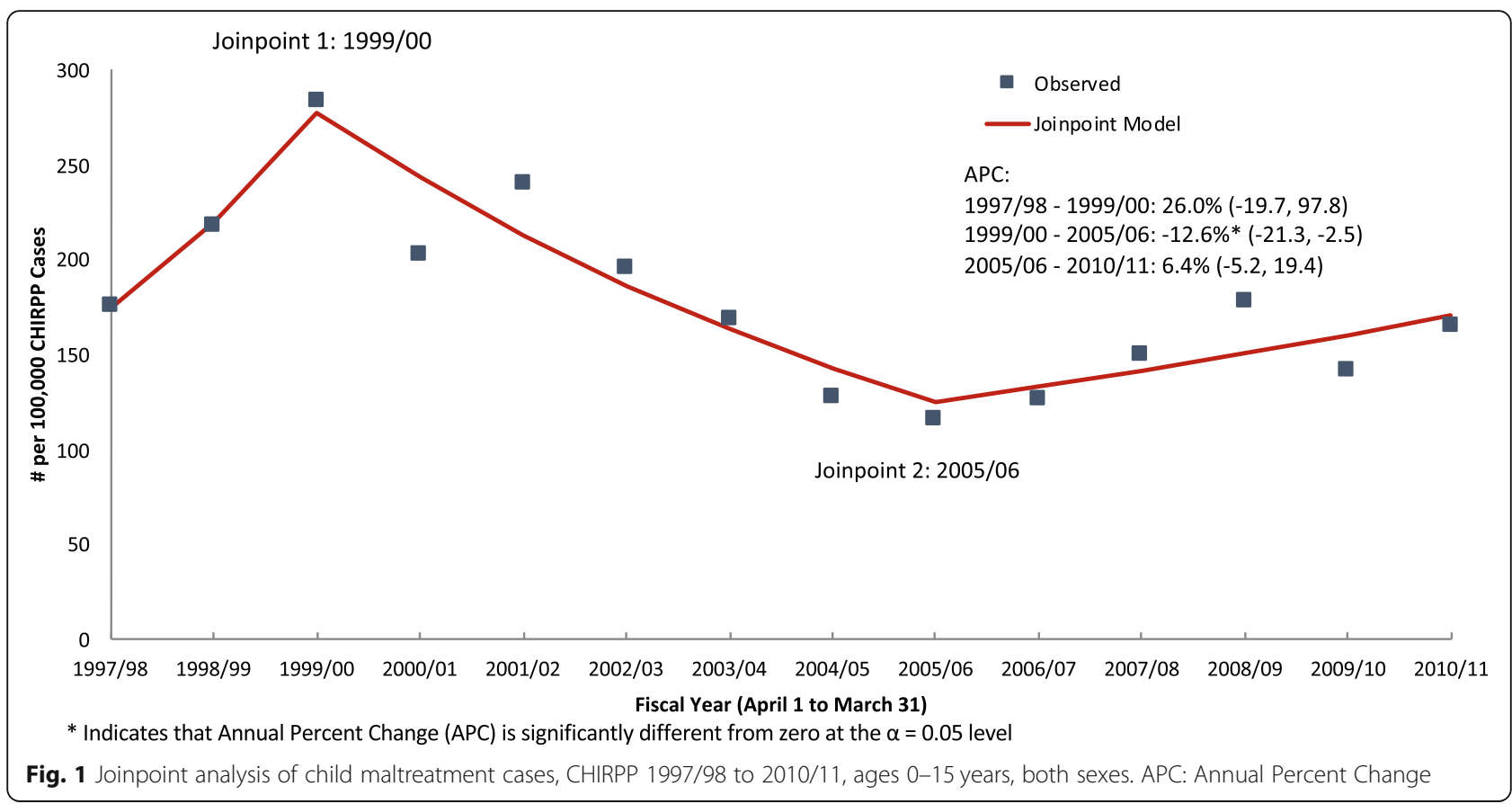

Of cases involving 'sexual assault by bodily force' the majority of reported perpetrators were known peers or adults followed by fathers or stepfathers and other male relatives. Friends were reported as perpetrators more often than a boyfriend or ex-boyfriend. Strangers were identified as perpetrators in $8 \%$ of sexual assault cases.

Of cases involving 'maltreatment by a parent or caregiver', family members, specifically fathers or step-fathers, followed by mothers or step-mothers and parents, were reported as responsible for injury due to maltreatment in the majority of cases. The male partner of a parent (i.e. mother's boyfriend) was identified most often among nonfamily members in a caregiving role.

Drug and/or alcohol use by perpetrators, victims or both was identified in $6 \%$ of all cases; the majority of which were for sexual assaults.

Non-health care professionals were identified as involved in $5 \%$ of cases. The majority of these cases indicated the involvement of child welfare (4\%) for 'maltreatment by a parent or caregiver.' Other nonhealth care professionals, such as law enforcement, were identified as involved in less than $1 \%$ of cases.

In $4 \%$ of cases, maltreatment reportedly occurred during a visitation period with a parent or step-parent. Finally, children were reportedly removed from their home in just over $1 \%$ of cases.

\section{Distribution of CM type by age and gender}

Table 2 presents the frequencies of CM types by age and gender. Female patients accounted for $88 \%$ of sexual assault cases while male patients tended to have slightly higher prevalence of physical abuse, neglect, and injury due to exposure to family violence. Physical abuse and sexual assault were more prevalent among older children (aged 12-15 years), while younger children were more likely to be brought to ED for neglect (1-3 years) and injury due to exposure to family violence ( $<1$ years). Sexual assaults were identified among all age groups with children under the age of one, followed by children 8 11 years showing the lowest levels.

\section{Discussion}

This study is the first to comprehensively assess $\mathrm{CM}$ cases in CHIRPP, including text field data. A total of $2200 \mathrm{CM}$ cases were identified for children under 16 years between 1997/98 and 2010/11. Our time trend analysis revealed a significant decrease in the capture of CM cases between 1999 and 2005. Text fields captured unique information such as types of CM resulting from direct physical injury as well as perpetrator characteristics and other details surrounding the injury event.

Joinpoint regression analysis was used to assess the trends in the capture of $\mathrm{CM}$ cases over the 14-year period. The main finding was a significant decrease in capture between 1999/00 and 2005/06. Child maltreatment (and other intentional injuries) has traditionally been difficult to capture in CHIRPP since the system was mainly designed to capture unintentional pediatric injuries [21-23]. It is possible that the decrease was partially due to difficulty in capturing these cases in some CHIRPP sites due to administrative and sensitivity issues. Recent improvements in the CHIRPP system [23] 
Table 1 Distributions of Variables Identified in CHIRPP Text Fields, n (\%)

\begin{tabular}{|c|c|c|c|}
\hline Text Field Variables & Sexual Assault by Bodily Force & Maltreatment by Parent or Caregiver & Total Cases \\
\hline Total Cases & $680(31)$ & $1520(69)$ & $2200(100)$ \\
\hline \multicolumn{4}{|l|}{ Maltreatment Type } \\
\hline Sexual Assault & $680(100)$ & 0 & $680(31)$ \\
\hline Physical Abuse & 0 & $1264(83)$ & $1264(57)$ \\
\hline Exposure to Family Violence & 0 & $55(4)$ & $55(3)$ \\
\hline Neglect & 0 & $46(3)$ & $46(2)$ \\
\hline Unspecified & 0 & $155(10)$ & $155(7)$ \\
\hline Fatalities & 0 & $8(0.5)$ & $8(0.4)$ \\
\hline \multicolumn{4}{|l|}{ Relationship to Perpetrator } \\
\hline \multicolumn{4}{|l|}{ Family Member } \\
\hline Parent & $-{ }^{a}$ & - & $145(7)$ \\
\hline Father or Stepfather & $79(12)$ & $600(39)$ & $679(31)$ \\
\hline Mother or Stepmother & - & - & $404(18)$ \\
\hline Relative $(\text { Male) })^{b}$ & $38(6)$ & $13(0.9)$ & $51(2)$ \\
\hline Relative $(\text { Female })^{c}$ & - & - & $20(0.9)$ \\
\hline Other Family Member ${ }^{d}$ & $27(4)$ & $5(0.3)$ & $32(1)$ \\
\hline \multicolumn{4}{|c|}{ Non-family Member in Caregiving Role } \\
\hline Foster Parent & 0 & $8(0.5)$ & $8(0.4)$ \\
\hline Partner of Parent (Male) & $16(2)$ & $47(3)$ & $63(3)$ \\
\hline Teacher or Day-Care Worker & $7(1)$ & $13(0.9)$ & $20(0.9)$ \\
\hline Babysitter & $8(1)$ & $23(2)$ & $31(1)$ \\
\hline \multicolumn{4}{|l|}{ Known Peer/Adult } \\
\hline Friend & $36(5)$ & 0 & $36(2)$ \\
\hline Boyfriend/Ex-boyfriend & $9(1)$ & 0 & $9(0.4)$ \\
\hline Neighbor & $14(2)$ & 0 & $14(0.6)$ \\
\hline Acquaintance & $17(3)$ & 0 & $17(0.7)$ \\
\hline Other Known Peer/Adult & $86(13)$ & $15(1)$ & $101(5)$ \\
\hline \multicolumn{4}{|l|}{ Unknown Peer/Adult } \\
\hline Stranger & $55(8)$ & 0 & $55(3)$ \\
\hline Drug/Alcohol Use & $98(14)$ & $43(3)$ & $141(6)$ \\
\hline \multicolumn{4}{|l|}{ Non-Health Care Professional } \\
\hline Child Welfare & $7(1)$ & $83(5)$ & $90(4)$ \\
\hline Other Non-Health Care & - & - & $29(1)$ \\
\hline Maltreatment During Visitation & $23(3)$ & $64(4)$ & $87(4)$ \\
\hline Removal of Child & - & - & $26(1)$ \\
\hline
\end{tabular}

${ }^{a}$ Cases less than 5 indicated with a dash due to suppression rules for small cell counts

${ }^{b}$ Relative (male) includes brothers, grandfathers and uncles

c Relative (female) includes sisters, grandmothers and aunts

d Other family members include cousins \& other relatives with unspecified gender

e Non-health care professional includes law enforcement and educational professionals

and efforts to understand and increase acquisition of intentional injuries [21,27] will help to improve case capture. The increasing, but not significant, trend in the last segment 2005/06 to 2010/11 suggests that case identification may be increasing, but continued surveillance is needed to analyze the trend beyond the study period.
Physical abuse was the most common type of CM captured in CHIRPP, followed by sexual assault. Our findings regarding the distribution of $\mathrm{CM}$ types are somewhat consistent with both Canadian and international ED studies that examine multiple types of $\mathrm{CM}$ [28-30]; although differences in timing of studies, 
Table 2 Child Characteristics by Primary Maltreatment Type, n (\%)

\begin{tabular}{|c|c|c|c|c|c|c|}
\hline \multirow[t]{2}{*}{ Characteristic } & \multicolumn{5}{|c|}{ Maltreatment Type } & \multirow[t]{2}{*}{ Total } \\
\hline & Sexual Assault & Physical Abuse & Neglect & Exposure to Family Violence & Unspecified & \\
\hline Total & $680(30.9)$ & $1264(57.5)$ & $46(2.1)$ & $55(2.5)$ & $155(7.0)$ & $2200(100)$ \\
\hline \multicolumn{7}{|l|}{ Gender $^{a}$} \\
\hline Female & $597(87.8)$ & $590(46.7)$ & $22(47.8)$ & $25(45.5)$ & $69(44.5)$ & $1303(59.2)$ \\
\hline Male & $83(12.2)$ & $673(53.2)$ & $24(52.2)$ & $30(54.5)$ & $86(55.5)$ & $896(40.7)$ \\
\hline \multicolumn{7}{|l|}{ Age Group } \\
\hline$<1$ & $7(1.0)$ & $165(13.0)$ & $14(30.4)$ & $22(40.0)$ & $55(35.4)$ & $263(12.0)$ \\
\hline $1-3$ & $111(16.3)$ & $222(17.6)$ & $22(47.8)$ & $14(25.5)$ & $65(41.9)$ & $434(19.7)$ \\
\hline $4-7$ & $154(22.7)$ & $278(22.0)$ & $7(15.2)$ & $7(12.7)$ & $21(13.5)$ & $467(21.2)$ \\
\hline $8-11$ & $60(8.8)$ & $232(18.4)$ & $--^{\mathrm{b}}$ & $6(10.9)$ & - & $309(14.0)$ \\
\hline $12-15$ & $348(51.2)$ & $367(29.0)$ & - & $6(10.9)$ & - & 727 (33.0) \\
\hline
\end{tabular}

a One case did not specify gender

b Cases less than 5 indicated with a dash due to suppression rules for small cell counts

sample size, age-ranges, and categories of maltreatment assessed, make direct comparisons challenging. Comparisons with child welfare data are also challenging since they illustrate a different picture of CM in Canada. In our study the prevalence of physical abuse and sexual assault were higher than reported in Canadian child welfare data, while exposure to family violence and neglect were comparatively low [7]. In CHIRPP, emotional maltreatment was rarely identified, and never in isolation, but made up $9 \%$ of substantiated child welfare investigations in 2008 [7]. Emotional maltreatment and neglect are difficult to capture in an ED setting [31]. For instance, neglect can present as physical injury from ingestions or inappropriate supervision [16], but intent is challenging to capture and emotional maltreatment rarely manifests in physical injury. Cases of co-occurring $\mathrm{CM}$ are well established in the literature, $[7,32-36]$ but were not well captured in CHIRPP. The low prevalence of co-occurring abuse in CHIRPP may be due to the fact that cases are identified through a specific injury event that requires immediate medical attention, and not through an investigation or assessment of a household.

In this study, a minority of cases indicated involvement with child welfare and $1 \%$ of children were removed from their homes. As CHIRPP does not usually provide information as to whether the child is receiving services from child welfare, or information regarding what happen after the initial injury event, our findings are likely underestimates. Our findings are however consistent with studies regarding health care professionals under-reporting CM to child welfare services [9] although an Ontario study found that the proportion of referrals to child welfare agencies for $\mathrm{CM}$ investigations from hospitals doubled between 1993 and 2013 [37]. An unexpected finding in our study was the number of cases that indicated injury due to $\mathrm{CM}$ during a visitation with a parent or step-parent. Although we did not find studies that dealt with this issue directly, child welfare data indicates that $13 \%$ of $\mathrm{CM}$ related investigations noted a child custody dispute [38].

Some patterns identified in our study were consistent with previous studies. As supported by the literature from Western countries, girls were significantly more likely to experience sexual assault $[8,28,32,39,40]$. In our study, sexual assaults increased for children age 1-7 years and increased again for adolescents $12-15$ years. This may demonstrate a pattern whereby family members perpetrating sexual assault are more likely to abuse younger children and non-family members, such as peers, dating or romantic partners, became the predominant perpetrators of sexual assault in adolescents. Abuse perpetrated against older children could also indicate a pattern of re-victimization [41, 42]. Consistent with previous studies our study also found that in cases of sexual assault perpetrators were more likely to be relatives, or known peers or adults, than strangers [43, 44].

Alcohol and drug use were identified in CM cases among both victims and perpetrators, especially in cases involving sexual assault. Child welfare data indicates that alcohol and drug abuse are risk factors for perpetrators in substantiated CM investigations [7, 45]. Previous research has shown a strong relationship between alcohol and sexual assault among female college students, and some evidence indicates that adolescent girls are more likely to experience physical force in alcohol-related sexual assaults than non-alcohol-related assaults [46].

In this study, fatal injuries occurred almost exclusively among young male children ( $<4$ years) from head related trauma. These findings are consistent with previously published Canadian studies, [18-20] and international studies $[5,28,30,47]$ that examined head injuries highlighting the young age and gender of patients. Traumatic brain injury in 
particular is associated with high mortality and morbidity in infants. Younger children are also more likely to experience prolonged consequences from their injuries [18, 48]. Also consistent with previous hospital studies [49], we found that fatalities among children in maltreatment categories were higher than other unintentional injury cases in CHIRPP (0.4\% vs. $0.1 \%)$. The higher prevalence of fatalities among children admitted to the ED due to CM in CHIRPP speaks to its importance as a surveillance tool for this vulnerable population.

\section{Limitations}

There are a number of limitations to this study. CHIRPP is not representative of the Canadian population making it challenging to compare with other CM data. Information provided in text fields are based on patients' interpretations of the questions and could be written or censored by patient's caregivers. Further, accounts of the injury event could be potentially flawed from recall errors and omissions. Lack of training of hospital staff and clinicians may impact their ability to recognize all types of $\mathrm{CM}$ and can result in under-reporting [50]. In addition, $\mathrm{CM}$ that does not result in serious injury is not captured in CHIRPP. It is also possible that less severe cases were misclassified and not identified by our search strategy. Physical assault directed toward children and adolescents from non-family members, or those not in a caregiving role, could be missed due to current CM intent codes. Although fatalities were captured in our study, CHIRPP is generally a poor source of fatalities because of the lack of information of cases past the initial injury event and because some cases bypass the ED altogether due to the severity of injuries.

\section{Strengths}

CHIRPP provides on-going, timely and detailed clinical data on different types of CM. Our study was conducted on a broader age-range of children and adolescents than previous studies. In addition to providing clinical details, CHIRPP text fields offer unique, case specific data which can provide details of the complexities of the injury event, including risk and protective factors [23]. Text fields serve to identify rare events and to increase the granularity of coding.

The examination of both $\mathrm{CM}$ codes and the accompanying text fields allows for a more detailed understanding of other CHIRPP categories (e.g. fatalities). At the time that these cases were recorded (1997/98-2010/11), text fields were limited to 120 characters. The electronic application of CHIRPP (eCHIRPP) launched in April of 2011, has an extended text field of 4000 characters providing the opportunity for more detailed information of the injury event. This expanded text field provides further opportunity to present details of complex cases.

\section{Recommendations}

The electronic application of CHIRPP, including its integrated data management tools, has enhanced timeliness and flexibility providing opportunities to enhance CHIRPP data collection [23]. In future, exploring the feasibility of expanding eCHIRPP to include all 5 types of $\mathrm{CM}$ intent code classifications would be valuable. Once CM has been identified using eCHIRPP, health care providers could be presented with a "mark all that apply" check list of each type of CM. This would allow for more in-depth capture of different types of $\mathrm{CM}$ and identify cases of co-occurring maltreatment. In addition, the term "sexual assault" could be reviewed and redefined as "sexual violence" to better reflect the diversity of cases perpetrated against children and adolescents. The analysis of CM in CHIRPP, however, should also include an analysis of text field data taking advantage of new techniques such as machine learning whenever possible. Our study has shown that they provide valuable details, and context, not available from the CHIRPP survey checklist alone.

\section{Conclusion}

In Canada, national sources of CM data are limited and the ability to examine the magnitude of this problem depends on the availability of diverse sources of data. While further research is required, the findings from this initial study indicate that CHIRPP could be a complimentary source of $\mathrm{CM}$ data. Although the examination of text fields increased the capture of different types of CM, CHIRPP is better suited to capture physical abuse and sexual assault. Further, the text field component of CHIRPP provides unique details of the CM injury event, in the majority of cases. This additional information also provides an opportunity to establish potential risk factors and to focus prevention and support to those exposed to CM.

\section{Abbreviations}

APC/AAPC: Average Annual Percent Change; CHIRPP: Canadian Hospitals Injury Reporting Prevention Program; CIS: Canadian Incidence Study of Reported Child Abuse and Neglect; CM: Child maltreatment; ED: Emergency department; PHAC: Public Health Agency of Canada

\section{Acknowledgements}

We would like to thank the Public Health Agency of Canada for providing the data for this study.

\section{Authors' contributions}

All authors contributed to this manuscript. AC, EG, LT, MH designed qualitative coding protocol. AC drafted and edited codebook for narratives with feedback from EG, LT, MH. AC, EG, LT, MH coded the text field data. EG conducted descriptive statistics for Tables. SM conducted time trend analysis and created Fig. 1. AC led the writing, drafting, and editing of the

manuscript. AC and LT wrote the discussion. All authors (AC, EG, LT, MH, SM, RS) contributed to the interpretation of findings and editing of the manuscript. All authors read and approved the final manuscript.

\section{Funding}

No external funding was provided. The work was conducted by authors as part of their regular duties or on a volunteer basis. 


\section{Availability of data and materials}

Data for CHIRPP are publicly available http://www.phac-aspc.gc.ca/injurybles/chirpp/index-eng.php by contacting the Centre for Surveillance and Applied Research, (Injury.Surveillance@phac-aspc.gc.ca).

\section{Ethics approval and consent to participate}

Each hospital in the CHIRPP program has undertaken their own ethics review. The data for this project were drawn from an existing deidentified surveillance database and the project thus did not undergo additional ethical review.

\section{Consent for publication}

Not applicable.

\section{Competing interests}

The authors declare that they have no competing interests.

\section{Author details}

${ }^{1}$ Public Health Agency of Canada, Ottawa, ON, Canada. ${ }^{2}$ Independent Researcher, Burnaby, BC, Canada. ${ }^{3}$ Université du Québec à Montréal, Montreal, QC, Canada.

Received: 19 August 2019 Accepted: 16 October 2019

Published online: 29 October 2019

\section{References}

1. Public Health Agency of Canada. The Chief Public Health Officer's Report on the State of Public Health in Canada, 2009: Growing Up Well - Priorities for a Healthy Future. Public Health Agency of Canada. 2009. https:/www. canada.ca/en/public-health/corporate/publications/chief-public-healthofficerreports-state-public-health-canada/report-on-state-public-healthcanada-2009.html. Accessed 5 Sept 2017.

2. Gilbert R, Widom C, S Browne K, Fergusson D, Webb E, et al. burden and consequences of child maltreatment in high-income countries. Lancet. 2009:373(9657):68-81.

3. Potter DA, Hovdestad WE, Tonmyr L. Sources of child maltreatment information in Canada. Minerva Pediatr. 2013;65(1):37-49.

4. Tonmyr L, Hovdestad WE. Public health approach to child maltreatment. Paediatr Child Health. 2013;18(8):411-3.

5. Farst K, Ambadwar PB, King AJ, Bird TM, Robbins JM. Trends in hospitalization rates and severity of injuries from abuse in young children, 1997-2009. Pediatrics. 2013;131(6):e1796-802.

6. Leeb RT, Fluke JD. Child maltreatment surveillance: enumeration, monitoring, evaluation and insight. Health Promot Chronic Dis Prev Can. 2015;35(8-9):138

7. Public Health Agency of Canada. Canadian Incidence Study of Reported Child Abuse and Neglect: Major Findings. Ottawa: Public Health Agency of Canada; 2010.

8. Afifi TO, MacMillan HL, Taillieu T, Cheung K, Turner S, et al. Relationship between child abuse exposure and reported contact with child protection organizations: results from the Canadian community health survey. Child Abuse Negl. 2015;46:198-206.

9. Tonmyr L, Li YA, Williams G, Scott D, Jack SM. Patterns of reporting by health care and nonhealth care professionals to child protection services in Canada. Paediatr Child Health. 2010;15(8):e25-32.

10. Gilbert R, Kemp A, Thoburn J, Sidebotham P, Radford L, et al. Recognising and responding to child maltreatment. Lancet. 2009;373(9658):167-80.

11. Newton AS, Zou B, Hamm MP, Curran J, Gupta S, et al. Improving child protection in the emergency department: a systematic review of professional interventions for health care providers. Acad Emerg Med. 2010; 17(2):117-25.

12. Guenther E, Knight S, Olson LM, Dean JM, Keenan HT. Prediction of child abuse risk from emergency department use. J Pediatr. 2009;154(2):272-7.

13. Wood JN, Medina SP, Feudtner C, Luan X, Localio R, et al. Local macroeconomic trends and hospital admissions for child abuse, 2000-2009. Pediatrics. 2012;130(2):e358-64.

14. Woodman J, Lecky F, Hodes D, Pitt M, Taylor B, et al. Screening injured children for physical abuse or neglect in emergency departments: a systematic review. Child Care Health Dev. 2010;36(2):153-64.
15. Louwers EC, Korfage IJ, Affourtit MJ, Scheewe DJ, van de Merwe MH, et al. Detection of child abuse in emergency departments: a multi-Centre study. Arch Dis Child. 2011;96(5):422-5.

16. Tiyyagura G, Gawel M, Koziel JR, Asnes A, Bechtel K. Barriers and facilitators to detecting child abuse and neglect in general emergency departments. Ann Emerg Med. 2015;66(5):447-54.

17. King WK, Kiesel EL, Simon HK. Child abuse fatalities: are we missing opportunities for intervention? Pediatr Emerg Care. 2006;22(4):211-4.

18. King WJ, MacKay M, Sirnick A. Canadian shaken baby study group. Shaken baby syndrome in Canada: clinical characteristics and outcomes of hospital cases. Can Med Assoc J. 2003;168(2):155-9.

19. Bennett S, Ward M, Moreau K, Fortin G, King J, et al. Head injury secondary to suspected child maltreatment: results of a prospective Canadian national surveillance program. Child Abuse Negl. 2011;35(11):930-6.

20. Fujiwara T, Barr RG, Brant RF, Rajabali F, Pike I. Using international classification of diseases, codes to estimate abusive head trauma in children Am J Prev Med. 2012:43(2):215-20.

21. Johnson D, Skinner R, Cappelli M, Zemek R, McFaull S, et al. Self-inflicted injury-Canadian hospitals injury reporting and prevention Program (CHIRPPSI): a new surveillance tool for detecting self-inflicted injury events in emergency departments. Can J Public Health. 2019;110(2):244-52.

22. Mackenzie SG, Pless IB. CHIRPP: Canada's principal injury surveillance program. Inj Prev. 1999;5(3):208-13.

23. Crain J, McFaull S, Thompson W, Skinner R, Do MT, et al. The Canadian hospitals injury reporting and prevention Program: a dynamic and innovative injury surveillance system. Health Promot Chronic Dis Prev Can. 2016;36(6):112.

24. Statistical Methodology and Applications Branch Surveillance Research Program, National Cancer Institute. Jointpoint regression program, version 4. 6.0.0 - April 2018. Bethesda, MD: National Cancer Institute.

25. National Cancer Institute. Average Annual Percent Change (AAPC). Rockville MD: National Cancer Institute. 2018. https://surveillance.cancer.gov/help/ joinpoint/setting-parameters/method-and-parameters-tab/apc-aapc-tauconfidence-intervals/average-annual-percentchange-aapc. Accessed 29 Oct 2018

26. Vaismoradi M, Turunen $\mathrm{H}$, Bondas $\mathrm{T}$. Content analysis and thematic analysis: implications for conducting a qualitative descriptive study. Nurs Health Sci. 2013;15(3):398-405.

27. Cloutier PF, Skinner R, Cappelli M, Zemek RL, Langill C, et al. Is It okay to ask? Public health surveillance of self-harm in the emergency department. Journal of the American Academy of Child \& Adolescent Psychiatry. 2016; 55(Supplement):s249-\$250.

28. King A, Farst K, Jaeger M, Onukwube J, Robbins J. Maltreatment-related emergency department visits among children 0 to 3 years old in the United States. Child Maltreat. 2015;20(3):151-61.

29. Keshavarz R, Kawashima R, Low C. Child abuse and neglect presentations to a pediatric emergency department. J Emerg Med. 2002;23(4):341-5.

30. Wheeler KK, Shi J, Xiang H, Haley KJ, Groner Jl. Child maltreatment in US emergency departments: imaging and admissions. Child Abuse Negl. 2017; 69:96-105.

31. Leetch AN, Leipsic J, Woolridge DP. Evaluation of child maltreatment in the emergency department setting: an overview for behavioral health providers. Child and Adolesc Psychiatr Clin. 2015:24(1):41-64.

32. Afifi TO, MacMillan HL, Boyle M, Taillieu T, Cheung K, et al. Child abuse and mental disorders in Canada. CMAJ. 2014;186(9):E324-32.

33. Dong M, Anda RF, Felitti VJ, Dube SR, Williamson DF, et al. The interrelatedness of multiple forms of childhood abuse, neglect, and household dysfunction. Child Abuse Negl. 2004;28(7):771-84.

34. Higgins DJ, McCabe MP. Multiple forms of child abuse and neglect: adult retrospective reports. Aggress Violent Behav. 2001;6(6):547-78.

35. Turner HA, Finkelhor D, Ormrod R. Poly-victimization in a national sample of children and youth. Am J Prev Med. 2010;38(3):323-30.

36. Turner S, Taillieu T, Cheung K, Afifi TO. The relationship between childhood sexual abuse and mental health outcomes among males: results from a nationally representative United States sample. Child Abuse Negl. 2017;66:64-72.

37. Fallon B, Filippelli J, Joh-Carnella N, Miller SP, Denburg A. Trends in investigations of abuse or neglect referred by hospital personnel in Ontario. BMJ Paediatr Open. 2019:3(1):e000386.

38. Fallon B, Lefebvre R, Seto M, Van Wert M. Malicious Referrals, Custody Disputes and Police Involvement in the Canadian Child Welfare System: Data Tables from the 2008 Canadian Incidence Study of Reported Child 
Abuse and Neglect. Department of Justice Canada. 2013. https://www. justice.gc.ca/eng/rp-pr/fl-lf/famil/mrcd-smcp/p1.html. Assessed 5 July 2019.

39. Burczycka M, Conroy S. Family violence in Canada: a statistical profile, 2015. Canadian Centre for Justice Statistics: Juristat; 2017. http://www.statcan.gc. ca/pub/85-002-x/2017001/article/14698/01-eng.htm. Accessed 5 Sept 2017

40. Stoltenborgh M, Van lizendoorn MH, Euser EM, Bakermans-Kranenburg MJ. A global perspective on child sexual abuse: meta-analysis of prevalence around the world. Child Maltreat. 2011;16(2):79-101.

41. Classen CC, Palesh OG, Aggarwal R. Sexual revictimization: a review of the empirical literature. Trauma Violence Abuse. 2005;6(2):103-29.

42. Hébert M, Moreau C, Blais M, Lavoie F, Guerrier M. Child sexual abuse as a risk factor for teen dating violence: findings from a representative sample of Quebec youth. J Child Adolesc Trauma. 2017;10(1):51-61.

43. Finkelhor D, Shattuck A, Turner HA, Hamby SL. The lifetime prevalence of child sexual abuse and sexual assault assessed in late adolescence. J Adolesc Health. 2014;55(3):329-33.

44. Hassan M, Killion C, Lewin L, Totten V, Gary F. Gender-related sexual abuse experiences reported by children who were examined in an emergency department. Arch Psychiatr Nurs. 2015;29(3):148-54.

45. Fallon B, Van Wert M, Trocmé N, MacLaurin B, Sinha V, et al. Ontario incidence study of reported child abuse and neglect 2013. Toronto: ON. Canadian Child Welfare Research Portal; 2015.

46. Young A, Grey M, Abbey A, Boyd CJ, McCabe SE. Alcohol-related sexual assault victimization among adolescents: prevalence, characteristics, and correlates. J Stud Alcohol Drugs. 2008;69(1):39-48.

47. Hobbs C, Childs AM, Wynne J, Livingston J, Seal A. Subdural haematoma and effusion in infancy: an epidemiological study. Arch Dis Child. 2005;90(9):952-5.

48. Kellogg ND. Evaluation of suspected child physical abuse. Pediatrics. 2007; 119(6):1232-41.

49. Leventhal JM, Martin KD, Gaither JR. Using US data to estimate the incidence of serious physical abuse in children. Pediatrics. 2012;129(3):458-64.

50. Scott D, Tonmyr L, Fraser J, Walker S, McKenzie K. The utility and challenges of using ICD codes in child maltreatment research: a review of existing literature. Child Abuse Negl. 2009;33(11):791-808.

\section{Publisher's Note}

Springer Nature remains neutral with regard to jurisdictional claims in published maps and institutional affiliations.

Ready to submit your research? Choose BMC and benefit from:

- fast, convenient online submission

- thorough peer review by experienced researchers in your field

- rapid publication on acceptance

- support for research data, including large and complex data types

- gold Open Access which fosters wider collaboration and increased citations

- maximum visibility for your research: over $100 \mathrm{M}$ website views per year

At $\mathrm{BMC}$, research is always in progress.

Learn more biomedcentral.com/submissions 